\title{
Carotid arteries in central retinal vessel occlusion as assessed by Doppler ultrasound
}

\author{
POLONA PETERNEL, DUŠAN KEBER, AND VIKTOR VIDEČNIK \\ From Trnovo Hospital of Internal Medicine, University Clinical Centre, Ljubljana, Yugoslavia
}

SUMMARY Doppler ultrasound was used to detect possible flow changes in the carotid arteries of patients with central retinal artery and vein occlusion. Twenty-three patients with central retinal artery occlusion (mean age 56, SD 11, years) were examined 4 to 48 months after the development of the occlusion and compared with age and sex matched control subjects with no history of any disease known to be associated with pathological changes in carotid vessels. Significant stenosis or occlusion of one or more carotid arteries was discovered in eight patients with retinal artery occlusion, while the ultrasonic findings were normal in all the controls $(p<0.005)$. Blood flow was evaluated by the same method in 16 patients with central retinal vein occlusion (mean age 57, SD 9 , years) six to 48 months after the event. A control group was chosen according to the same criteria as in previous comparison. Pathological ultrasonic findings were observed neither in the patients with retinal vein occlusion nor in the control group. The results suggested a possible aetiological relation between pathological changes in the carotid arteries and occlusion of the central retinal artery, but not occlusion of the central retinal vein.

The pathogenesis of central retinal artery occlusion (CRAO) is based on a few case reports and observations of the natural course of the disease. Since most of the patients are more than 60 years old, it has been presumed that in most cases CRAO is the consequence of thrombosis or embolism. ${ }^{2}$ Angiographic demonstration of thrombosis of the internal and external carotid artery, with the thrombus extending into the ophthalmic region, has been an occasional finding. ${ }^{3}$ On the other hand embolism of the retinal arteries has for long been confirmed by post-mortem examination as a possible complication of the stenosed internal carotid artery. ${ }^{4}$ Some clinical reports describe patients with carotid artery disease who suffered an embolism of the retinal artery. ${ }^{56}$ Occasionally retinal embolism is provoked by diagnostic and therapeutic interventions on an atherosclerotic carotid artery. ${ }^{2}$

The pathogenesis of central retinal vein occlusion (CRVO) is even less well understood and has been attributed to diminished blood flow ${ }^{7}$ or to a thrombotic diathesis. ${ }^{89}$ It has been presumed

Correspondence to Polona Peternel, MD, Trnovo Hospital of Internal Medicine, University Clinical Centre, Riharjeva 24, 61000 Ljubljana, Yugoslavia. that an abnormal carotid artery flow and a reduced ophthalmic arterial perfusion pressure play a significant part in the development of retinal venous changes. Atherosclerotically stenosed internal carotid or retinal arteries may slow down the blood flow through the retinal veins by a siphon effect and therefore establish conditions that are favourable for the development of venous thrombosis. Some clinical reports ${ }^{11}$ and experimental data ${ }^{11}$ drew attention to the connection between carotid artery disease and CRVO. According to these speculations the cause of both CRAO and CRVO might partly originate in the diseased arteries that supply the eye.

Since occlusion of a central retinal vessel is not rare, it is rather surprising that there has been no systematic study on the state of the carotid vessels in these patients.

In the past few years we have treated 29 patients with CRAO and 16 with CRVO with streptokinase. The results have already been published..$^{12}$ The aim of the present study was to reinvestigate these patients and examine their carotid arteries by the Doppler ultrasound technique to check whether retinal vessel occlusion (CRAO or CRVO) could be considered as a marker of symptomatic carotid artery stenosis. 


\section{Patients and methods}

PATIENTS

Between 1979 and 1985, 29 patients with CRAO and 16 with CRVO were admitted to our department to receive streptokinase treatment. The diagnosis of CRAO and CRVO was confirmed by an ophthalmologist using well known criteria. ${ }^{13}$ In brief, CRAO was defined as a sudden and severe visual impairment to $0 \cdot 1$ or less, accompanied by ischaemic oedema of the retina and narrowing of retinal arteries. Direct ophthalmoscopic evidence of arterial embolism was found in only one patient. The duration of symptoms before the institution of fibrinolytic therapy was 2.5 to 24 (mean 9.5 ) hours in 20 patients and 1.2 to 14 (mean 4.3) days in nine patients. CRVO was defined as a severe visual impairment to 0.2 or less, accompanied by venous engorgement, numerous intraretinal and peripapillary haemorrhages, and cottonwool spots. The duration of symptoms before the institution of fibrinolytic therapy was two hours in one patient, and 1 to 14 (mean 6.1) days in 15 patients.

It should be stressed that only patients eligible for thrombolytic therapy were included. Therefore these series represented selected patients (with either CRAO or CRVO) who had none of the following contraindications for thrombolytic therapy: active internal bleeding, cerebrovascular accident or operation within two months, any major operation, organ biopsy, puncture of non-compressible blood vessel, postpartum period, thoracocentesis, paracentesis, lumbar puncture, recent serious trauma, cardiopulmonary resuscitation (within 10 days of onset of these conditions), uncontrolled severe hypertension, coagulation defects, and age over 70 years. ${ }^{14}$

Between the previous study ${ }^{12}$ and present study three patients with CRAO died, the cause of all deaths being stroke. In addition three patients with CRAO were unwilling to participate.

Among 23 patients with CRAO (mean age 56 (SD 11) years) there were six women and 17 men. They had suffered CRAO four to 48 (mean 29) months before the present study. Some of them had symptoms of atherosclerosis before the onset of CRAO: four patients had myocardial infarction; one of these also suffered a stroke, and a second one had his leg amputated because of gangrene. In the time between the diagnosis of CRAO and this study two further patients suffered transitory ischaemic attacks and one had a second stroke, while the patient with peripheral arterial disease lost the other leg. Arterial hypertension was present in seven and diabetes mellitus in two; four patients smoked.

Among 16 patients with CRVO (mean age 57 (SD 9) years), there were six women and 10 men. They had suffered CRVO six to 48 (mean 28) months before the present investigation. None of them had any evident clinical signs of atherosclerosis before CRVO. Between the diagnosis of CRVO and the present study angina developed in one patient. Arterial hypertension was present in seven and diabetes mellitus in 3; three patients smoked.

In the two control groups there were 23 and 16 age and sex matched patients; they had been admitted to our department for various health problems. Besides age and sex, which were the same as in the corresponding experimental groups the only criteria for inclusion were the absence of historical and clinical data of central retinal vessel occlusion, stroke, transitory ischaemic attack, ischaemic heart disease, and peripheral arterial disease. In the CRAO control group arterial hypertension was present in five and diabetes in two; four subjects smoked. Corresponding figures for the CRVO control group were four, one, and three subjects, respectively.

\section{METHODS}

The examination was performed with a bidirectional continuous-wave Doppler ultrasonic device, with 4 and $8 \mathrm{MHz}$ probes (Kranzbühler 762). The examination included the determination of blood flow direction and velocity, together with wave form analysis in the common, internal, and external carotid arteries as well as in the supratrochlear or supraorbital arteries. Flow changes in the supraorbital or supratrochlear arteries were also examined during a compression test. The criteria of $50 \%$ or higher stenosis or occlusion were followed according to Barnes and coworkers. ${ }^{15}$ The examining physician was not informed of the diagnoses of the patients and control subjects.

The differences in frequencies of pathological tests between the various groups were calculated by the Fisher's two-tailed exact test for attributive data. ${ }^{16}$

\section{Results}

In eight patients, seven men and one woman, mean age 57 (SD 6) years, with CRAO, Doppler ultrasound measurement revealed significant carotid stenosis or occlusion of one or more carotid arteries. In two patients occlusion of the ipsilateral internal carotid artery was found, together with stenosis of either the common or internal carotid artery on the contralateral side. Four patients showed ipsilateral stenosis of the internal carotid artery. The patient who had suffered CRAO of both eyes showed evidence of bilateral internal carotid stenosis. One patient fulfilled the criteria of contralateral internal carotid stenosis (Table 1).

No pathological changes were found in the carotid 
Table 1 Carotid artery stenoses or occlusions in eight patients with central retinal artery occlusion (CRAO) as detected by Doppler ultrasound measurement

\begin{tabular}{llll}
\hline Sex & Age & CRAO & Pathological changes in carotid arteries \\
\hline M & 62 & R & Occlusion of ICA R and stenosis of ICA L \\
M & 64 & R & Occlusion of ICA R and stenosis of CCA L \\
M & 47 & R & Stenosis of ICA R \\
M & 57 & R & Stenosis of ICA R \\
M & 57 & R & Stenosis of ICA R \\
M & 55 & L & Stenosis of ICA L \\
F & 63 & R + L & Stenosis of ICA R and L \\
M & 52 & R & Stenosis of ICA L \\
\hline
\end{tabular}

$\mathrm{ICA}=$ internal carotid artery. $\mathrm{CCA}=$ common carotid artery. $\mathrm{R}=$ right. $\mathrm{L}=$ left. $\mathrm{M}=$ male. $\mathrm{F}=$ female.

arteries of patients with CRVO and the control subjects. The difference in the incidence of pathological findings in the CRAO group was statistically significant as compared with the control group as well as with the CRVO group (Table 2).

\section{Discussion}

Evidence of a possible link between central retinal vessel occlusion and pathological changes in carotid arteries has been incomplete, because the invasive or non-invasive examinations of the carotid arteries have not been performed systematically in this disease.

In eight patients with previous CRAO Doppler ultrasound revealed haemodynamically significant stenoses or occlusions of at least one internal carotid artery, while no changes were found in the control subjects. In all patients but one the stenosis or occlusion was on the side of the affected eye. This observation coincided with the results of Cote and coworkers, ${ }^{17}$ who had found that most patients with occlusion of the internal carotid artery had suffered

Table 2 Results of Doppler examination of the carotid arteries in patients with central retinal artery $(C R A O)$ and vein $(C R V O)$ occlusion and in the control group

\begin{tabular}{lll}
\hline & $\begin{array}{l}\text { Pathological } \\
\text { findings }\end{array}$ & $\begin{array}{l}\text { Normal } \\
\text { findings }\end{array}$ \\
\hline $\begin{array}{l}\text { CRAO group } \\
\mathbf{n}=23\end{array}$ & $8^{*}$ & 15 \\
$\begin{array}{l}\text { Control group } \\
\mathbf{n}=23\end{array}$ & 0 & 23 \\
$\begin{array}{l}\text { CRVO group } \\
\mathbf{n}=16\end{array}$ & 0 & $\mathrm{p}<0.005$ \\
$\begin{array}{l}\text { Control group } \\
\mathbf{n}=16\end{array}$ & 0 & 16 \\
& 0 & \\
\hline
\end{tabular}

*significantly different from CRVO group $(\mathrm{p}<0 \cdot 001)$. stroke on the side of the affected carotid artery, and only a minority had been affected on the opposite side. Our patient who had suffered two strokes showed evidence of internal carotid artery occlusion on the same side as CRAO, and stenosis of the common carotid artery on the other. Stenoses of both internal carotid arteries were discovered in the patient who had suffered CRAO of both eyes in a two-month interval.

Data from Doppler ultrasound blood flow measurements in patients with different types of retinal ischaemia are relatively rare. Ringelstein and coworkers $^{18}$ described nine patients with CRAO. In five of them Doppler ultrasound measurements were normal, while in the other four an occlusion or stenosis of the carotid artery was found on the same side as CRAO and confirmed by $x$-ray angiography.

Three of our CRAO patients died of stroke in the interval between the previous ${ }^{12}$ and the present study. The state of their carotid arteries was not examined, but it can be speculated that these patients would increase the proportion of CRAO patients with diseased carotid arteries. Moreover, there are two additional reasons for supposing that the true frequency of diseased carotid arteries was probably higher than that suggested from our results. The first is the diagnostic limitations of the Doppler ultrasound technique. We followed the opinion of most investigators who considered the result of the examination to be pathological only when the diagnostic criteria of $50 \%$ or greater stenosis or occlusion were fulfilled. ${ }^{19}$ Haemodynamically less significant stenoses were therefore lost with these criteria. The possibility of retinal embolism originating from ulcerated plaques, with minimal narrowing of the carotid artery, could not be excluded.

The second reason is the selection of patients in our study. Since the patients were selected not only regarding the presence of the disease, but also regarding the absence of contraindications for thrombolytic therapy, our conclusions hold true only for this subgroup of patients with no absolute or major relative contraindication for fibrinolytic treatment (age over 70 years, severe arterial hypertension, recent stroke). Several of these exclusion criteria are known to be associated with an increased incidence of atherosclerotic changes. In an unselected group of patients with CRAO a higher proportion of patients with carotid artery stenosis would probably be found.

Our results indicated that changes in the carotid arteries were associated with CRAO. This association does not prove that carotid artery disease causes CRAO, but it does at least indicate that CRAO is a marker of carotid artery disease. It is well known that patients with CRAO are also at risk for other complications of the central nervous system and 
share a high mortality rate due to advanced atherosclerosis. ${ }^{210}$

The examination of carotid arteries in our study was performed after and not before or at the time of CRAO. Therefore this study did not provide definite evidence on the causal relationship between the carotid artery disease and CRAO. However, if not a direct embolic consequence of proximal atherosclerotic lesions, CRAO is at least a marker of widespread atherosclerotic disease in the carotid tree.

Previously no data have been available on Doppler ultrasound examination of carotid arteries in patients with CRVO. Our results showed that none of the patients with CRVO and the corresponding control group had any significant changes in the carotid arteries. They also indicated that the pathological process leading to CRVO was probably different from that leading to CRAO. The different natural courses of CRVO and CRAO also speak in favour of this suggestion: in contrast to CRAO, CRVO is not related to an increased mortality."

In conclusion, we might say that the assumption examined in this study of the aetiological relation between pathological changes in the carotid arteries and CRVO can be rejected. On the other hand the association between carotid artery stenosis or occlusion and CRAO was confirmed. This finding argues for the close examination of carotid arteries in every patient with CRAO, which is in agreement with an earlier recommendation. ${ }^{22}$

The work was supported by the Slovenian Research Community, Grant C3-0175-326.

\section{References}

1 Karjalainen K. Occlusion of the central retinal artery and arterial branch arterioles. Acta Ophthalmol (Kbh) 1971; 109 (suppl): $1-95$.

2 Appen RE, Wray SH, Cogan DG. Central retinal artery occlusion. Am J Ophthalmol 1975; 79: 374-81.

3 Countee RW, Vijayanathan T, Chavis P. Recurrent retinal ischemia beyond cervical carotid occlusions. J Neurosurg 1981; 55: $532-42$.
4 McBrien DJ. Bradley RD. Ashton N. The nature of retinal emboli in stenosis of the internal carotid artery. Lancet 1963: i: 697-9.

5 De Bono DP, Warlow CP. Potential sources of emboli in patients with presumed transient cerebral or retinal ischaemia. Lancet $1981 ;$ i: $343-5$.

6 Goodwin JA, Gorelick PB, Helgason CM. Symptoms of amaurosis fugax in atherosclerotic carotid artery disease. Neurology 1987; 37: 829-32.

7 Hayreh SS. So-called central retinal vein occlusion. I. Pathogenesis, terminology, clinical features. Ophthalmologica 1976; 172: $1-13$.

8 Walsh PN, Goldberg RE, Tax RL. Magargal LE. Platelet coagulant activities and retinal vein thrombosis. Thromb Haemost 1977; 38: 399-406.

9 Peduzzi M, De Rosa V, Fonda S, Coccheri S. Haemostatic studies in retinal vein occlusion. Fibrinolytic response to venostasis as a prognostic factor for spontaneous recanalization. Thromb Res 1981; 24: 105-18.

10) Zegarra H, Gutman FA, Zakov N, Carim M. Partial occlusion of the central retinal vein. Am J Ophthalmol 1983; 96: 330-7.

11 Spertus AD, Slakter JS, Weissman SS, Henkind P. Experimental carotid occlusion: funduscopic and fluorescein angiographic findings. $\mathrm{Br}$ J Ophthalmol 1984; 68: 47-57.

12 Boljka M, Peternel P. Kolar G. Vidensě J. Die thrombolytische Therapie bei Zentralgefässverschlüssen. Klin Monatshl Augenheilkd 1984; 185: 395-6.

13 Duke-Elder S, Dobree JH. Diseases of the retina. London: Kimpton, 1967; 66-94.

14 Sharma GVRK, Cella G, Parisi AF. Sasahara AA. Thrombolytic therapy. N Engl J Med 1982; 306: 1268-82.

15 Barnes WR. Nix L, Rittgers SE. Audible interpretation of carotid Doppler signals. Arch Surg 1981; 116: 1185-9.

$16 \mathrm{Zar}$ JH. Biostatistical analysis. Englewood Cliffs: Prentice-Hall, 1974: 291-5.

17 Cote R, Barnett HJM, Taylor DW. Internal carotid occlusion: a prospective study. Stroke 1983: 14: 898-902.

18 Ringelstein EB, Korber N, Zeumer H. Hunold W. Arterielle retinale Durchblutungsstörungen: eine dringende Indikation zur Doppler-sonographischen Untersuchung der CarotisStrombahn. Klin Monatsbl Augenheilkd 1983; 182: 133-40.

19 D Alton JG, Norris JW. Carotid Doppler evaluation in cerebrovascular disease. Can Med Assoc J 1983; 129: 1184-9.

20 Rossmann H. Treatment of retinal arterial occlusion. Ophthalmologica 1980; 180: 68-74.

21 Rubinstein K, Jones EB. Retinal vein occlusion: long term prospects. BrJ Ophthalmol 1976; 60; 148-50.

22 Ackerman RH. Non-invasive carotid evaluation. Stroke 1980; 11: $675-8$.

Accepted for publication 11 May 1989. 